\title{
The epidemiology of sudden infant death syndrome
}

\author{
J. F. MURPHY \\ From the Department of Child Health, University Hospital of Wales, Cardiff \\ R. G. NEWCOMBE \\ From the Department of Medical Statistics, Welsh National School of Medicine, Cardiff
}

J. R. SIBERT

From the Llandough Hospital, Penarth, South Glamorgan

\begin{abstract}
SUMMARY Ninety-nine cases of sudden infant death syndrome were identified among 47413 liveborn deliveries to Cardiff residents during the years 1965-73 and 1975-77. Nineteen predictive factors available on the Cardiff Birth Survey record were evaluated individually and jointly in terms of their power to identify risk of sudden and unexpected infant death.
\end{abstract}

In a large proportion of postneonatal infant deaths, clinical history and post-mortem examination do not reveal pathological conditions sufficient to account adequately for the death. In a prospective study carried out by the working party for early childhood deaths in Newcastle, ${ }^{1}$ three-quarters of the postneonatal deaths studied were classified as sudden and unexpected. The loss of an infant in this way is particularly hard for the parents to bear, because in the absence of a clearcut physiological explanation they commonly feel the cause must lie in what they have or have not done; such feelings of guilt may be shared by members of the attending primary care team. ${ }^{2}$ The fact that most postneonatal infant deaths defy adequate explanation constitutes a major defect in the body of medical knowledge.

A major problem hindering research arises from the essentially negative nature of the diagnosis: observer differences in completeness of necropsy technique and interpretation and in certification of the cause of death. ${ }^{34}$ Two main areas of research are related to sleep apnoea and associated cardiorespiratory pathophysiology in young infants ${ }^{5-7}$ and the study of epidemiological data. ${ }^{89} \mathrm{We}$ have examined the medical and social factors of all Cardiff infants and established a scoring system weighting these factors in such a way as to discriminate infant deaths attributed to sudden infant death syndrome (SIDS) from all other live births.

\section{Material and methods}

The Cardiff Birth Survey records demographic, social, and medical information on all births to Cardiff residents. ${ }^{10}$ We examined all such births occurring during the 12 years 1965-1973 and 1975-1977; the year 1974 was excluded because of incomplete ascertainment of cases.

Every infant under the age of 1 dying suddenly and unexpectedly at home, who had been well before death, underwent post-mortem examination by the duty consultant pathologist. The post-mortem technique did not include any additional specialised biochemical, virological, or histological procedures. Among such infants, those without congenital abnormalities or any other pathological findings sufficient to account for death were included in the SIDS group. In the early years of the study non-specific diagnoses such as 'mild bronchiolitis' had been used; latterly the expression SIDS was used by all pathologists.

The control group consisted of all remaining liveborn infants born to Cardiff residents during the study period.

The incidence of SIDS was tabulated by all variables recorded by the Cardiff Birth Survey. Nineteen variables were identified which gave independent information bearing on prediction. Certain factors were excluded in favour of other 
highly correlated but more discriminatory variables: duration of marriage, history of abortion, inadequate assessment and correction of maternal anaemia, gestational age at delivery, neonatal infection and recourse to antibiotic therapy. Birth weight was a relatively weak predictor on the present data and a case could be made for its exclusion also; nevertheless it was included in the predictor because of its importance in other studies and its widespread acceptance as an easily determined indicator of prognosis. Numerous other variables examined did not significantly correlate with SIDS: maternal height and weight, marital status, medical, obstetric and oral contraception history, type of antenatal care, use of ultrasound and cervical cerclage, excess weight gain during pregnancy, toxaemia, bacilluria, version, presentation, Rhesus sensitisation, place of delivery, presence of a doctor at delivery, use of oxytocin or prostaglandin, anaesthesia or analgesia, scalp sampling, and the Apgar score.

Table 1 lists the 19 predictive variables thus selected. The 19 wards of the City of Cardiff were segregated into three groups according to the type of housing in an arbitrary way before the data were examined. Three wards could be unequivocally labelled 'good', consisting almost entirely of well-maintained owner-occupied property. The wards termed 'poor' consisted almost entirely of either old or council housing. The intermediate group included areas of an intermediate standard and others whose boundaries contained widely different standards of housing. 'Complications of pregnancy' means the occurrence of any of the following: antepartum haemorrhage; rupture of membranes 24 hours before the onset of labour; venereal disease; deep-vein thrombosis or embolism. Season of birth was dichotomised in January and July after examining the data and the true significance of the effect was confirmed using a more appropriate Edwards test. ${ }^{11}$

In Table 1 the relative risk (RR) is obtained by dividing the incidence of SIDS in a subgroup by that in the whole series. This definition of $R R$, which differs from that commonly used in epidemiology, is appropriate in the present context (Newcombe RG, unpublished observations). Each $R R$ is then converted to an additive score component of 10 $\log _{10} R R$, rounded to the nearest whole number.

In this way a scoring system, system I, was set up, which could allocate to any infant a score representing the risk of SIDS. An infant is given an initial score of 100 , and 19 components, one for each factor, are added to or subtracted from this baseline. A zero score is given to a factor whose value is not known.
The distribution of each score component and the total score among the 99 cases and 47314 controls were examined. Assessment of discriminatory power was made in terms of a statistic $P$, the probability that a randomly selected case of SIDS would have scored higher than a control selected independently at random. ${ }^{12-14}$ The off-diagonal entries of the correlation matrix of the 19 score components among all 47413 infants were examined, in order to confirm that assumptions of independence were not substantially violated.

A second scoring system was constructed, using equal weights. In this analysis each score of +1 or above was replaced by +1 and each zero or negative score was replaced by zero.

A third scoring system was also derived, based on a minimal set of salient variables: maternal smoking, maternal age, area of residence, and birth weight, each given a weight as in system I.

\section{Results}

Ninety-nine cases of SIDS were identified among 47413 liveborn infants, an incidence of $2 \cdot 1$ per 1000 live births. The incidence is cross-tabulated with the 19 predictive factors in Table 1 . These are arranged in decreasing order of predictive power; values of $P$ for smoking and employment of partner are 0.647 and $0 \cdot 520$.

The 19 score components are not strongly correlated with one another: 137 of the 171 entries in the correlation matrix are less than $0 \cdot 1$ in absolute value.

Table 2 indicates the mean, $\mathrm{SD}$, and range of the total score, and the value of $P$, for systems I, II, and III. It can be seen that some information is lost in simplifying system I to either II or III. System I assigns a score of 107 or higher to 5057 or $11 \%$ of the 47413 infants, and these include $49 \%$ of the cot deaths (see Figure).

\section{Discussion}

This study demonstrates that an infant from a certain type of family has a higher than average risk of suffering a cot death-essentially a deprived family of low social class living in a poor area. The mother is typically young, and yet of relatively high parity; many mothers in our study smoked and were poor clinic attenders. Labour was easy, with a rapid second stage; the infant was more likely to be male or twin and to have spent some time in the special care baby unit. Although none of these factors adequately explains the death, their appearance as epidemiological factors does seem plausible. 
The epidemiology of sudden infant death syndrome

Table 1 Factors differing significantly between 99 SIDS and 47314 control births

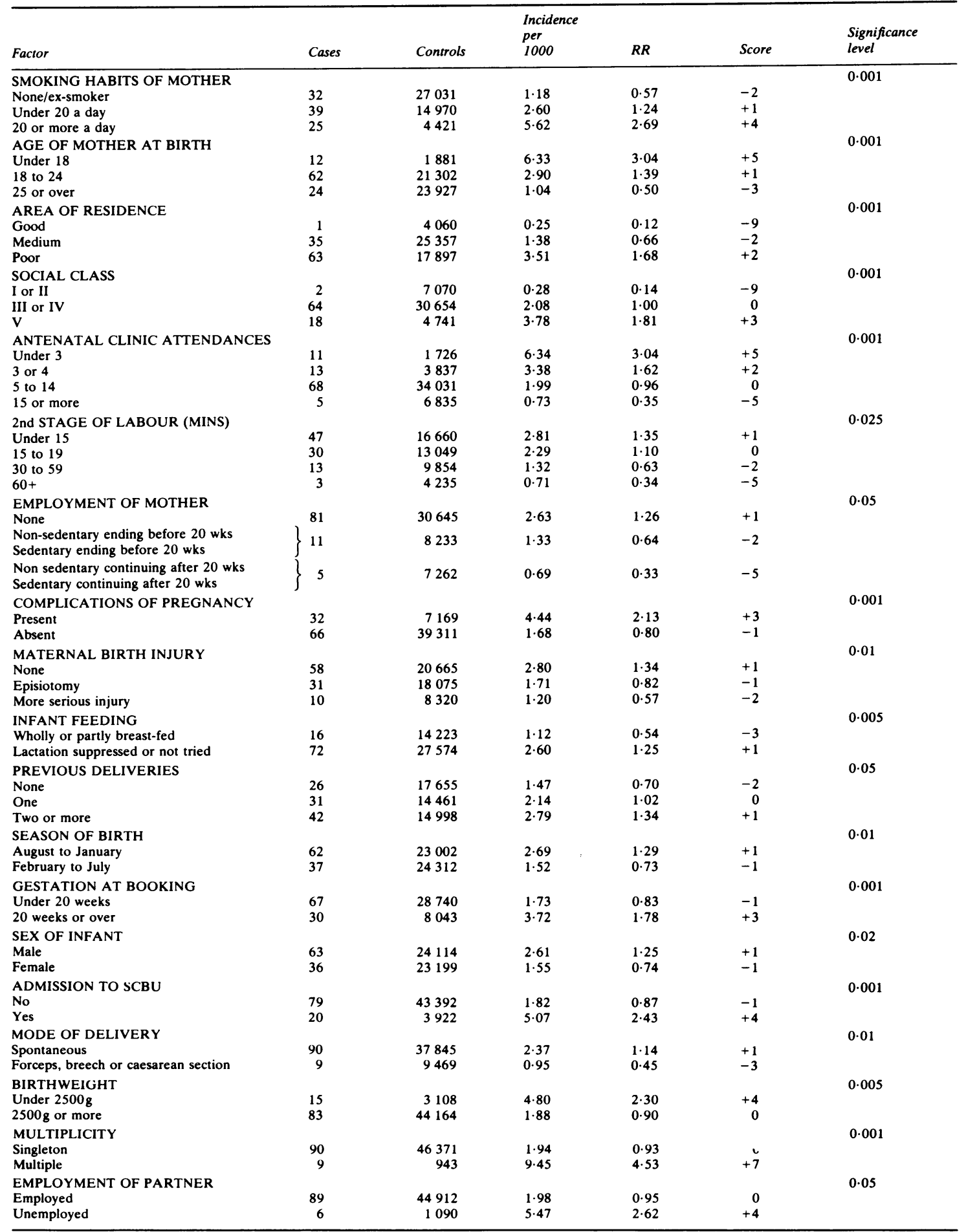


Table 2 Performance of scoring systems to predict sudden infant death syndrome

\begin{tabular}{|c|c|c|c|c|c|c|c|}
\hline System & $\begin{array}{l}\text { No. of } \\
\text { factors }\end{array}$ & Weights & Group & Mean & $S D$ & Range & $\boldsymbol{P}$ \\
\hline I & 19 & Unequal & $\begin{array}{l}\text { Cases } \\
\text { Controls }\end{array}$ & $\begin{array}{r}106.4 \\
93.6\end{array}$ & $\begin{array}{r}9.0 \\
10.9\end{array}$ & $\begin{array}{l}85-126 \\
48-133\end{array}$ & 0.816 \\
\hline II & 19 & Equal & $\begin{array}{l}\text { Cases } \\
\text { Controls }\end{array}$ & $\begin{array}{l}108 \cdot 8 \\
106 \cdot 1\end{array}$ & $\begin{array}{l}2 \cdot 3 \\
2 \cdot 3\end{array}$ & $\begin{array}{l}103-114 \\
100-116\end{array}$ & 0.786 \\
\hline III & 4 & Unequal & $\begin{array}{l}\text { Cases } \\
\text { Controls }\end{array}$ & $\begin{array}{r}102 \cdot 3 \\
97 \cdot 9\end{array}$ & $\begin{array}{l}4.5 \\
4.9\end{array}$ & $\begin{array}{l}86-111 \\
86-115\end{array}$ & 0.750 \\
\hline
\end{tabular}

Infants born between August and January are at highest risk because they reach the most susceptible age during the winter months. The effect of maternal smoking may be understood in terms of either damage in utero or passive smoking by the neonate.

The measure of predictive power used, $P$, takes the value 1.0 when discrimination is perfect, 0.5 when the distributions in cases and controls are indistinguishable. The level of prediction obtained, $0 \cdot 816$, is similar to that found by Carpenter et al. ${ }^{9}$

We compared the scoring system with that obtained by studying a group of 80 Cardiff children who had suffered non-accidental injury (NAI). Murphy et al $^{15}$ reported such a system, based on the Cardiff Birth Survey, using equal weights. For purposes of cross-validation an unequally weighted version of the NAI score was used. The SIDS and NAI scores had eight factors in common, which were predictive of both outcomes: maternal age, social class, city ward, maternal smoking, poor use of antenatal care, lack of employment during pregnancy, admission to the special care baby unit, and artificial feeding. Birth weight was predictive of NAI and was included in the SIDS predictor. Two further factors related to NAI were marital status and low maternal weight. The NAI predictor can predict NAI with a power of $P=0.858$ and SIDS with a power of $P=0 \cdot 768$. Conversely the SIDS score predicts SIDS and NAI with $P=0.816$ and 0.756 respectively. Thus the two predictors do not delineate quite the same high-risk group but they are in close agreement. On epidemiological and social grounds much the same group of infants is at high risk of both SIDS and NAI.

These findings support those of Roberts $e t$ al, ${ }^{16}$ who demonstrated a threefold increased risk of infant death among siblings of abused children. In our study a high-risk group consisting of $11 \%$ of all infants who score 107 or more would include $49 \%$ of the cases of SIDS. Half the fatalities would occur in the low-risk group and only $1 \%$ of the high-risk group would be expected to die. This relatively weak predictive power renders any formal follow-up system for high-risk infants very costly in manpower and would be expected to make little impact on the incidence of SIDS. Such a prediction system is, however, a valuable means of identifying a group of infants on which to base further research. ${ }^{5}$ It may also be used in health care planning to delineate those city wards and families which may benefit most from additional supportive health services. ${ }^{17}$

The predictive power is unlikely to improve until it is possible to identify risk factors of a physiological rather than a social nature. This study does, however, once again underline the impact of the social circumstances of the family on the well-being of the infant.

We thank Dr. G. M. Bryant and Dr. C. M. Weaver for help and suggestions, and Miss Deborah Kelly and Miss Linda Richard for typing the manuscript.

Reprints from Dr. R. G. Newcombe, Department of Medical Statistics, Welsh National School of Medicine, Heath Park, Cardiff CF4 4XN.

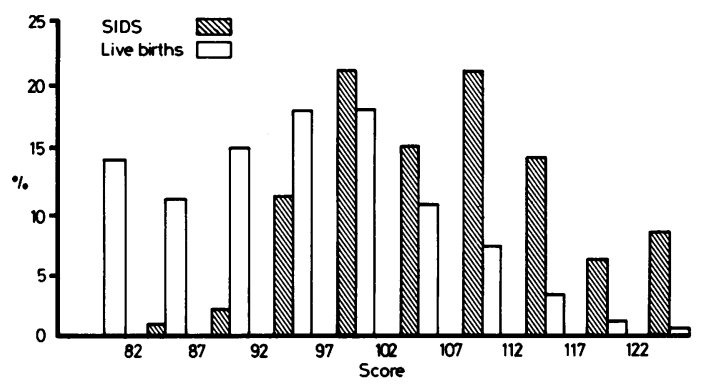

Figure Distribution of score $I$ in cases of sudden infant death syndrome and in all live births. 


\section{References}

${ }^{1}$ Working party for early childhood deaths in Newcastle. Newcastle survey of deaths in early childhood 1974-76, with special reference to sudden unexpected deaths. Arch Dis Child 1977; 42: 828-35.

${ }^{2}$ Anonymous. Reactions to sudden infant death. Lancet 1980; ii: 683 .

${ }^{3}$ Weatherall JAC, White GC. Variations in the recording of sudden infant death syndrome on death certificates. Office of Population Censuses and Surveys Studies on Medical and Population Subjects No. 31. London: HMSO, 1976: 61-9.

${ }^{4}$ Standfast SJ, Jereb S, Janerich DT. The epidemiology of sudden infant deaths in upstate New York.JAMA 1979; 241: $1121-4$

${ }^{5}$ Steinschneider A. Prolonged apnea and sudden infant death syndrome. Clinical and laboratory observations. Pediatrics 1972; 50: 646-54.

${ }^{6}$ Franks CI, Watson JBG, Brown BH, Foster EF. Respiratory patterns and risk of sudden unexpected death in infancy. Arch Dis Child 1980; 55: 595-9.

${ }^{7}$ Vesselinova-Jenkins C. Model of persistent fetal circulation and sudden infant death syndrome. Lancet 1980; ii: $831-4$.

${ }^{8}$ Fedrick J. Sudden unexpected death in infants in the Oxford Record Linkage area. Br J Prev Soc Med 1974; 28: 93-7.
${ }^{9}$ Carpenter RG, Gardner A, McWeeny PM, Emery JL. Multistage scoring system for identifying infants at risk of unexpected death. Arch Dis Child 1977; 52: 606-12.

${ }^{10}$ Andrews J, Davies K, Chalmers I, Campbell H. The Cardiff Birth Survey: development, perinatal mortality, birth weight and length of gestation. In: Genetic and population studies in Wales. Harper PS, Sunderland E, eds. Cardiff: University of Wales Press, 1982.

${ }^{11}$ Edwards $\mathrm{JH}$. The recognition and estimation of cyclic trends. Ann Hum Genet 1961; 25: 83-7.

${ }^{12} \mathrm{Gini}$ C. Il concetto di transvariazione e le sue prime applicazioni. Giornale degli Economisti e Rivista di Statistica (Rome) 1916; 53: 13-43.

${ }^{13}$ Berkson J. Cost-utility as a measure of the efficiency of a test. J Am Stat Assoc 1947; 42: 246-55.

${ }^{14}$ Birnbaum ZW. On a use of the Mann-Whitney statistic. Proceedings of the 3rd Berkeley symposium on mathematical statistics and probability 1956; 1: 13-7.

${ }^{15}$ Murphy JF, Jenkins J, Newcombe RG, Sibert JR. Objective birth data and the prediction of child abuse. Arch Dis Child 1981; 56: 295-7.

${ }^{16}$ Roberts J, Lynch MA, Golding J. Post-neonatal mortality in children from abusing families. $\mathrm{Br}$ Med $J$ 1980; 281: 102-4.

${ }^{17}$ Madeley RJ. Relating child health services to needs by the use of simple epidemiology. Public Health 1978; 92: 224-30. 